\title{
Research on the interaction between sports training mode and institutional culture under the Internet
}

\author{
Zhang Bo, Wei Hongyan \\ Jining Medical University, Rizhao, Shandong China, 276826,
}

Keywords: colleges and universities; sports training mode; pluralistic construction; cultural atmosphere.

Abstract: with the deepening of quality education, sports in Colleges and universities in China have been gradually taken seriously. In order to improve the efficiency and quality of physical education, the construction of sports training mode has become a universal teaching method in Colleges and universities. In the background of the current Internet era, the construction of college sports training mode is also diversified. In order to promote the good interaction between the construction of Gao Xiaoyu sports team and the cultural atmosphere of the campus colleges and universities, it is necessary to further optimize the construction of sports teams and construct measures less than the cultural atmosphere in the management of colleges and universities, and find and solve them in time. . This article will analyze the current sports training mode and the current situation of the development of the sports training mode in our universities and explore the effective interaction between the sports training mode and the cultural atmosphere of the colleges and universities in order to promote the scientific and healthy development of the college sports training mode.

In order to cultivate the students' awareness of sports and improve their enthusiasm for physical training, many colleges and universities have set up a sports training model, which has effectively improved the students' sports level. However, in the current construction of college sports training mode, most of the problems exist in the management, focusing on the improvement of the level of the sports team. For most students, the training of the high level sports team is not possible. It makes it difficult for the construction of the training team to implement the actual physical education teaching ${ }^{[1]}$. Therefore, the construction of college training team should take diversified ways according to the actual situation of the students, so that every student can participate in the sports training, cultivate the students to develop good construction habits and sports consciousness, so as to further promote the construction of the cultural atmosphere of the management of colleges and universities.

\section{The current form of formation of training teams in China's colleges and Universities}

In the current university training team, the purpose and organization of the training team are different. Through the investigation and analysis of the formation of training teams in various universities, it is found that the current organization of university training teams mainly consists of 
the following three ways of formation. The first is the physical training mode organized by the school for the completion of the work of the outside school, for the school level training team; the second is the sports training mode organized by the Department to complete the various sports activities and competitions held in the school, the training team for the Department and the third kind of teachers or students. Well organized training courses or sports associations are mainly organized in the form of clubs and clubs. They are group training teams or sports club training team ${ }^{[2]}$. In the construction of college sports training mode at present, the students' sports clubs and sports clubs are the main ways to promote the development of sports education, which should be popularized in Colleges and universities. Therefore, it is necessary to strengthen the management of the sports training mode, not only to improve the model role of the training team, but also to stimulate the initiative and enthusiasm of the students, and to promote the smooth development and popularization of the sports work.

\section{The present situation of the training team in China's colleges and Universities}

In the form of sports training mode in China's colleges and universities, the form of the school level training team and the students' sports associations are supplemented. The two training forms are all after class sports training, and the leadership is managed by the school leaders. The extracurricular training of the school level training team is set up by the school physical education committee and the Department of teaching and research, based on the Faculty of the University and the equipment of the sports field. It is organized and managed by the school. The funds are also allocated by the financial department of the school. The members of the school level training team have a strong interest and a higher level of interest in a sports project. Or students with a certain potential, aiming at improving the level of school sports training mode, so as to represent schools to participate in some sports competitions outside school ${ }^{[3]}$. The specific situation of the training ground in Colleges and universities in China is as follows.

\subsection{The training goal of the training team in Colleges and Universities}

For the school level training team, it is mainly organized by the school, by the leadership of the school department and the management of the teachers at different levels. The purpose of the training is to achieve excellent achievements and improve the reputation of the school in the event of competition activities outside the school. Therefore, the funding of the school level training team is mainly derived from the input from the school. It is important to stimulate the enthusiasm and initiative of teachers and students through good results in competitions.

For the Department training team, it is organized by the staff of various departments and departments, mainly by the department leaders, class counselors and students. The purpose of the organization is to represent the sports meetings and competitions held within the school. Its funds are derived from the input of the departments and departments to stimulate the hospital by participating in various activities. It is a student's initiative and initiative in sports activities, cultivating students' interest in sports and promoting students to develop good sports habits ${ }^{[4]}$.

For sports clubs or sports clubs, most of them are the organization of physical education teachers in Colleges and universities, which are managed by students. The purpose of the training is to enable students to develop their own sports hobbies or sports skills and enrich their spare time. At present, it is one of the most favorite sports training modes for college students. This training team model is based on interests and hobbies, and has a wide range of participation, effectively realizing the students' expression of their own sports hobbies, but also the refraction of the cultural atmosphere of the school associations. 


\subsection{The training form of college training team}

In the school level training team, the school is managed by the school, and the training plan is mostly made by the school. The training plan is based on the long term technology. Occasionally, the training plan will be in the need of the competition activities, and the corresponding short-term plan is made. The training form of the school level training team is mostly based on the training, and the training staff are mostly appointed by the school and are responsible for the training. At the same time, it is also responsible for the daily management of the school level training team.

In the training team of the Department, the main leaders of the Department and the teachers of our school are managed and organized, and the training plan is mostly based on short-term training, and the students are trained in the form of training. Most of the trainers are composed of the students of the sports department, the physical education teachers and the higher skills of the sports skills of the Department. In this form of training, the trainer is only responsible for the training plan and the daily physical training, and the management of the training team is responsible for the ${ }^{[5]}$ by its organization.

In the sports club and the sports club, the sports club is organized by the school physical education teacher, the mobility of the members is large, most of which are mainly short-term cycle training. The sports club organizers are responsible for their daily management and training, while the sports club training teams are mostly organized by the students, mainly by the organizers and the adults. Staff members are co managed, coaches are responsible for students with higher technical skills in the associations, and when necessary, school sports teachers can be instructed.

\subsection{Training time of training teams in Colleges and Universities}

In terms of training time, the training time of the three types of training teams is different due to the different grades and classes. In order to not affect the study of the students' cultural curriculum, the spare time training plan takes the student curriculum design as a reference in time arrangement, so as to achieve the aim of optimizing the training effect. In the time arrangement of the school level training team, the daily training mainly concentrates on the students' extracurricular activity time so that the students can have the opportunity to train at the same time. At the same time, the training team members will be trained before the holiday on the holidays, due to the need of the competition. For the training team of the Department, the training time is mainly extracurricular activities. Sometimes, for the intramural competition, the training team will arrange the time in advance and carry out training in the time section of the members, for example, the training of the two weekends, seldom in holidays or cold and summer holidays. For the club training team, the organizers often take the time as the main part, most of which will be arranged in the amateur fixed time periods of the organizers' weekends and holidays, and the members can reasonably control their participation time ${ }^{[6]}$ according to their time arrangement and the design of the club time. In the training of the students' sports associations, the time arrangement is flexible. As the organizers and participants are all students, they usually have fixed spare time; sometimes they will participate in some competitions and activities out of the common interests of the members, and organize training activities according to their own time, which has strong randomness and flexibility.

\section{The construction of interactive mode between sports training mode and college culture management atmosphere.}

The present situation of the development of sports training mode in China's colleges and universities is analyzed. Because the organizational form of the school level training team and the department level training team is relatively single, it not only has a great obstacle to the 
development of the management of the training team, but also increases the financial burden of the colleges and universities, and has a great adverse effect on the long-term development of the training team. Sports clubs and the sports associations organized by students are the main forms and motive forces to promote the development and popularization of physical training in Colleges and universities. Therefore, the construction of sports training patterns in Colleges and universities presents a diversified form. In this paper, the construction of diversified sports training mode and the cultural division of College community management are mainly aimed at the construction of sports training mode. The construction of the internal interaction model.

\subsection{The construction goal of the interactive model}

In the course of the development of sports training in Colleges and universities, it is necessary to build a diversified training organization system, guide the interaction of different forms of training teams to complement each other, and coordinate the development, so as to promote the construction of the cultural atmosphere of the management of the campus colleges and universities in the course of the construction and development of the training team, so as to build a harmonious sports training model and the campus College Association. Manage the interactive mode of cultural atmosphere. In the sports training system, the construction of the training team and the cultural atmosphere of the campus colleges and universities are not two individual individuals. In the process of construction and management, we can strengthen the interaction between the two, according to the advantages and functions of the two, and manage it as a whole, promote the development and promote the sports at the same time. The interaction between training mode and the management culture atmosphere of campus colleges and universities can achieve the goal of sports construction and development in Colleges and universities, ${ }^{[7]}$.

\subsection{The construction of the interactive mode of different forms of training teams}

In the college sports training mode, the form is different because of the different organizational personnel and management personnel. However, the training team, the student sports club and the sports club are all the school training teams, and the different types of sports training modes have a thousand and a few links. In the interactive system of college sports training mode diversification and the cultural atmosphere of college community management, the students' sports clubs, sports clubs and departments of sports training are centered on the school training team. In the daily management and training, there is a good complementary relationship between each other.

In sports competitions, students with high level of sports skills in every sports training mode can join the training team and participate in competition and training on behalf of the school if they meet the needs of the school training team. In daily training, students can choose their own training time according to their spare time, referring to the course design, time arrangement and training nature of each training team's sports training. In order to reduce the financial burden of the school, in order to reduce the financial burden of the school, we can refer to the diversified investment ways of the sports club or the student sports association, increase the members of the training team and improve the initiative of the after-school training so as to promote the popularization of the extracurricular sports training. In addition, it can take advantage of the profit club to collect fees, increase the financial income of the school level training team, reward the students with excellent results in material and spirit, and stimulate the students' initiative of physical training ${ }^{[8]}$. For the training effect, the training teams can make their own good results publicly rewarded and stimulate the other training teams to create an effective competitive model for each training team. As for the members of different training teams, because of the strong mobility of each training team, students can voluntarily carry out flow training according to the training arrangements of other training 
teams and their own actual conditions. For example, the excellent members of the school level training team can be in charge of training and guidance in other training teams and improve their skills. To promote exchanges and interaction with other training team members is conducive to the cultivation of their own comprehensive qualities and the construction of cultural atmosphere in the management of campus associations.

\subsection{In the interactive mode, the relationship between the management atmosphere and the training team is established.}

In the interactive mode, the construction of the cultural atmosphere for the management of the campus colleges and universities includes the construction and development of the different training teams of the school. The construction of the sports training mode and the construction of the cultural atmosphere in the management of the campus colleges and universities belong to each other That is to say, the development of the different sports training modes and the campus colleges and universities. The strong degree of the cultural atmosphere of community management has a direct influence, and the management culture atmosphere of the campus colleges and universities can also directly affect the development and popularization of the sports training model.

In college sports, after class training, as its main content, it has an effective and active role for students to participate in sports and the operation of sports mechanism in Colleges and universities. At the same time, it is also beneficial to the popularization and popularization of "National Fitness Program", "lifelong sports" and "sunshine sports activities", and popularize [9]. According to the characteristics of physical education, the students' collective consciousness is cultivated and their ideological and moral level is raised during the course of sports training, so that students can form a positive learning attitude in the cultural atmosphere of rich and colorful colleges and universities. At the same time, school spirit and sports spirit can be combined to promote the development of campus culture. Therefore, in the construction of the interactive system of diversified construction of sports training mode and the cultural atmosphere of college community management, colleges and universities should attach importance to the training of students' after-school training, in order to ensure their physical and physical function, to strengthen their educational value and publicity effect, and to create a diversified cultural atmosphere for the management of campus colleges and universities, so as to be full of the cultural atmosphere. The spiritual needs of students in learning and life are ${ }^{[10]}$. In addition, we should integrate the campus culture into the extracurricular sports training activities, improve the students' participation in the extracurricular sports activities, strengthen the attraction of the management culture of the campus colleges and universities, improve the sports level of the students effectively, and achieve the purpose of strengthening physical fitness and Tao Yiqing exercises, so as to make the sports training mode. Diversified construction and the construction of cultural atmosphere in community colleges and universities will form an interactive whole and effectively promote the sustainable development of college sports.

\section{Concluding remarks}

In a word, the diversified construction of sports training mode in Colleges and universities helps the formation of cultural atmosphere in the management of colleges and universities, and a strong cultural atmosphere in Colleges and universities is conducive to the popularization and popularization of sports after-school training. Therefore, in the current sports construction of colleges and universities, the construction of diversified sports training mode and the management of colleges and universities are constructed. The interaction system of cultural atmosphere is of great necessity. In the students' extracurricular time, carrying out physical training can effectively 
mobilize the students' enthusiasm for sports, not only to improve the development of sports construction in Colleges and universities, but also to achieve the purpose of strengthening physical fitness. It can also promote the formation of students' lifelong sports consciousness, and to a certain extent, is conducive to the long-term development of students. Therefore, in the process of building the cultural atmosphere for the management of the campus colleges and universities, the university should attach importance to the construction of the sports training mode, promote the diversification of its development, promote the interaction between the two, and form a good sports construction system.

\section{References}

[1] Song Qinghua. The construction of the diversified sports training mode of college students and the interaction of cultural atmosphere in the management of colleges and universities and colleges and universities [J]. Hubei sports science and technology, 2014 (6): 526-529.

[2] Li Baocheng. The construction of diversified sports training mode of college students and the cultural atmosphere of college associations, and the establishment of [J]. technology outlook, 2015 (2).

[3] Mu Dao Kai. Analysis of physical and mental health of college students after school sports training [J]. education, 2015 (26): 129-130.

[4] Yang Rongbin. An interactive study on the characteristics of college sports and the management culture construction of campus colleges and universities [J]. Zhejiang sports science, 2013, 35 (3): 80-81.

[5] Wu Zongmei, Liu Zhiying. Study on the interaction between extracurricular sports and the management culture of campus colleges and universities [J]. Journal of Yanshan University (PHILOSOPHY AND SOCIAL SCIENCE EDITION), 2005, 6 (S1): 185-186.

[6] Dong Chao, Dong Cuixiang, Ji Liu. Current situation and Countermeasures of Shanghai amateur training coach team construction [J]. Sports journal, 2015 (1): 100-103.

[7] Huang Caihong, Zhigang. Harmonious interaction between university sports associations and management culture of campus associations [J]. Contemporary sports technology, 2015, 5 (18): 92-93.

[8] Jilin. Interactive development of physical education in Applied Universities and community management culture in campus universities [J]. tax payment, 2017 (13): 129-130.

[9] Li Tao. Study on the interaction mechanism between the management culture of campus associations and the cultivation of College Students' socialist core values [J]. Cultural and educational materials, 2017 (9): 60-62.

[10] Wang Shufang, Zang Wei, Li Guojin. The interaction between university sports competition and campus culture construction [J]. Intelligent City, 2017 (2).

Zhang Bo (1980-), male, nationality: Han, native place: Xintai Shandong,, unit: Jining Medical University, master, lecturer, educational background: undergraduate course, His research interests include Physical Education and Training.

Wei Hongyan (1981-), Female, nationality: Han, native place: Jining Shandong, unit: Jining Medical University, master, lecturer, educational background: undergraduate course, Her research interests include Computer Education and Training of scientific and technological innovation. 